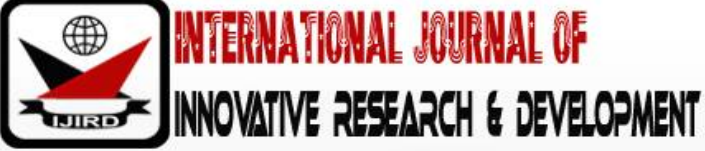

ISSN 2278 - 0211 (Online)

\section{Implications of some Cultural Practices on Maternal Mortality: A Study of some Selected Rural Areas of Kano State Nigeria}

\author{
Abdurraheem, Anifat \\ Lecturer, Department of Sociology, Federal University Dutsin, Nigeria \\ Ilim, Moses Msughter \\ Lecturer, Department of Sociology, Federal University Dutsin, Nigeria \\ Amali, Suleiman \\ Lecturer, Department of Sociology, Federal University Dutsin, Nigeria
}

\begin{abstract}
:
The major aim of this study was to examine some selected cultural practices affecting maternal mortality among married women of reproductive age in rural areas of Kano state.

A multistage selection sampling process involving cluster and simple random sampling methods were used in selecting 1,120 women between the ages of 15 and 49 for questionnaire administration in 4 local government areas of Kano state namely Bichi, Gaya, Kibiya and

Shanono. Similarly, purposive sampling technique was used in selecting respondents for the IDI and participants for the FGDs. Both primary and secondary data were utilised in the study. The primary data gathered through questionnaire were analysed quantitatively while the data gathered through FGDs sessions and IDI were qualitatively analysed to complement and support the quantitative analysis The major findings of the study indicates that marternal mortality is associated with early marriage, preference for home delivery, nutritional status of women and lack of decision making power of women. The study therefore, concluded that to understand the problem of maternal mortality as a whole, we must understand the influence of some cultural practices on maternal health. It is based on this that the study recommends that a robust enlightenment campaign be carried out to educate men and women in the society particularly those in the rural areas on the harmful cultural practices that are detrimental to the health of women in their reproductive ages. The study also suggest that policies geared towards uplifting women's status in the society should be encouraged and enforced. This can be done by vigorously pursuing girl child education in Kano State.
\end{abstract}

Keywords: Maternal mortality, Reproductive age, home delivery, nutritional status and decision making power..

\section{Introduction}

Motherhood, a positive, fulfilling and cherished experience by most women is often associated with sufferings, ill health and even death. This valued and precious part of life is among the most hazardous experiences that women often engage in most times without being aware of the risk or danger they are in. Pregnancy and childbirth complications are the leading causes of death and disability among women of reproductive age, especially in developing countries. Across the world, about 830 women die in pregnancy and childbirth every dayand it is estimated that about 303,000 women died from the complications of pregnancy in the year 2015. Out of this figure developing countries accounted for about $99 \%$ of maternal deaths, withAfrica and Asia each accounting for more than half of this figure. Only about $1 \%$ occurred in developed regions of the world (World Health Organization(WHO), 2018). Providing further insight into the nature and extent of maternal mortality in both developed and developing societies, the WHO (2014) report revealed that one out of every 51 women dies during pregnancy or childbirth in sub-Saharan Africa compared with just one in 4,000 in Europe.

In Nigeria, more than twenty years into the war against maternal deaths, the country still has one of the worst maternal mortality statistics in the world. Nigeria is second to India in global estimates of maternal mortality with a maternal mortality ratio of 576 per 100,000 live births,according to WHO (2014). Nigeria loses about 145 women of childbearing age every day and a woman's chance of dying from pregnancy and childbirth is 1 in 51. (NPopC, 2014). The prevalence of high maternal mortality rates in Nigeria generally and particularly in Northern Nigeria is a thing of great concern and the goals of safe motherhood seems to be eluding many governments. To draw unprecedented attention to reproductive health and rights and to gender equity and equality, the Programmes of Action of International Conference on Population and Development of 1994and the Fourth World Conference on Women of 1995 were created in an attempt to tackle these issues. In the same vein, the Maputo Declaration and Action Plan and the Millennium Development Goals all call for concerted actions to reduce maternal mortality, promote maternal health and empower women with knowledge, so that 
they are more useful to themselves, family and communities (WHO, UNFPA, UNICEF 2004). However, adequate knowledge of maternal mortality is a prerequisite if these goals are to be achieved.

As defined by World Health Organization, Maternal Mortality is the death of a woman while pregnant or within forty two (42) days of the termination of the pregnancy irrespective of the duration and size of it, from any cause related or aggravated by the pregnancy or its management from accidental or incidental causes (WHO 1992).Various studies conducted have shown that certain types of women are at greater risk of maternal mortality in Nigeria. These include too young (less than 18 years old), too old (above 35 years old), too sick, too many children (having above four deliveries) and too closely spaced childbirths (less than two years apart). Other risk factors exposing women to maternal mortality include high levels of malnutrition, unsafe abortions and the HIV/AIDS pandemic (USAID, 2008; WHO, UNICEF, UNFPA,2004; Yar'zever et al, 2010).

The most common medical causes of maternal deaths are infection, hypertensive disorder, prolonged or obstructed labour, unsafe abortion, hemorrhage, ruptured uterus and toxemia (WHO, 2014). If promptly and effectively managed, these complications can be prevented. But in Nigeria, the problems stem not only from inadequate health services but also as a result of the interplay of many antecedent factors, such as the social, the cultural, the economic, and the political coupled with very high fertility. Such sex specific health problems spread out into well-known cultural difficulties and discriminations meted out on women in third world countries. Most of these women would have been underfed, neglected and overworked as children or even in their adulthood or both. Others are often poor and illiterate and subjected to harmful traditional practices and even denied equal social status in the society.

Nigeria by nature is a patriarchal society where women are discriminated against from infancy. Gender disparity has been observed with women generally receiving less attention than men, especially in rural areas. North Western Nigeria consists primarily of Hausa and Muslims ofwhom men hold the primary decision making power in the society, including the decision to visit a health care centre. Even in the face of an emergency, it is expected that a woman must wait until the husband or in-laws give consent (Adamu, 2003). The practice is even more noticeable in rural areas. That is why many women within these communities are often trapped in a cycle of ill health exacerbated by child bearing and hard physical labour (USAID, 2008)).

A lot of empirical and theoretical information has been generated on issues relating to maternal mortality but despite the amount of work published on the topic, maternal mortality continues to occur at high rates and solutions to the problem are still not clear. This is perhaps because the scientific researches on maternal mortality focus mainly on clinical factors. However to understand the problem of maternal mortality wholly, we must have an insight into the cultural factors leading to the clinical issues of maternal mortality and the role norms and values as well the traditional practices of a people play in influencing the choices or lack of it that exacerbates the problems associated with maternal mortality.

In spite of modernization, the culture of the people, particularly in the rural areas of Kano State, still plays a dominant role in shaping their reproductive behavior. In his study Yar' zever (2014) revealed that while education is likely to enhance female autonomy, so that women develop greater confidence and capability to make decisions about their own health in urban centres, rural women are more readily influenced by traditional practices that are contrary to the modern health practices related to maternal health. Similarly, findings by Yar'Zever and Sa'id (2013), on the factors affecting knowledge and utilisation of maternal health facilities.In Kano, particularly in the rural areas, suggest that the traditional conception of early marriage practice also plays a significant role in the knowledge of maternal health services and the age at which girls are given out in marriage. This is thus an important determinant of their knowledge and uses of reproductive health care practices. The respondents were asked about their agse at their first marriages. $.75 \%$ of them married at less than 18years while the remaining $96 . .7 \%$ urban respondents married 18 years and above as against $25 \%$ rural respondents. The major objective of this study is thus tolook at the roles played by some selected cultural practices and the effects of such roles on maternal mortality in therural areas of Kano State.

\subsection{Statement of the Research Problem}

The health condition of women in Nigeria is extremely poor and the rates of maternal mortality in the society are among the highest in the world. Nigeria's maternal mortality rate is 576 per 100,000 live births, which is the second highest in the world (NpopC, 2014). The lifetime risk of dying during child birth is approximately 1 in 51 as compared to 1 in 4,000 in industrialized nations, making Nigeria one of the worst countries for women to deliver babies in the world (WHO, 2014). While maternal mortality ratios continue to decline globally, they are increasing in Nigeria and the rate is higher among women living in rural areas and in poorer communities due to certain practices mostly rooted in the culture.. Some of these cultural practices that are known to have impeded the maternal health of women are associated with home delivery, early marriage and too frequent childbirth (Beddada, 1982). Evidence shows that cultural practices are some of the reasons why mothers choose to deliver at home in preference to the hospital. This is because they consider home delivery as natural and cheap in terms of financial cost. Relatedly another cultural factor known to have negative effects towards maternal mortality in rural communities include the belief (mostly among Northerners) that woman's nakedness should not be seen by another man aside her husband. On the strength of this belief system, most men prefer their wives to deliver at home, compromising their maternal health in the process and hence the high incidence of maternal mortality. Other factors associated with cultural beliefsinclude the financial capacity of the family in relation to a delivery facility, transportation costs in moving to the hospital, fear of the demands from hospitals and the associated bureaucratic bottlenecks. Moreover, most of these deliveries are not attended to by skilled medical personnel but often times by traditional birth attendants (TBAs) and these births are often associated with the high risk of maternal deaths since unskilled TBAs are not trained to identify and attend to complicated labour. 
Similarly, Yar'zever and Duze (2013) argued that early marriage among Northerners has gradually become the norm rather than the exception. It must however be noted that while early marriage and early pregnancy are supported by cultural beliefs among people in the North, young adolescent face a higher risk of complications and death as a result of pregnancy than older women (WHO, 2018). In Kano state, it is a common practice for parents to arrange the marriage of their young daughters particularly to older men. In rural areas, marrying out children of ten to fifteen years of age is premised on the value to protect them from falling victim to teenage pregnancy (Yar'zever and Duze, 2013). However, Apav-Igba, Ilim and Abdurraheem (2019), WHO (2014) and Abdurraheem, Ilim \& Amali (2019) have all shown that complications usually arise from pregnancy and childbirth and the harmful effects of child pregnancy on the health of the mother may be severe. Early marriage predisposes a woman to having many children to psychological and other health problems.

Poverty in Northern Nigeria has a feminine face. This has been proven both by qualitative and quantitative data, including indirect extrapolations based on the characteristics of poverty. It was found out by the United Nations Fund for Population (UNFPA) that the poor comprise predominantly women of rural dwellers, those in remote areas, the poorly educated, those in informal sector occupations and those poorly paid wage earners. All these lead to the poor nutritional status of women, low level of literacy and poor knowledge of child spacing (UNFPA,2008).

Maternal situation among the Hausa speaking people of Kano state is greatly influenced by the culture of patriarchy, which gives men more power over women in virtually all spheres of family decision life. Women are being excluded from sensitive family discourse, such as family planning, family size and access and use of maternal health facilities. This is usually hinged on cultural beliefs and values designed and sustained by men in order to maintain their domination and subjugation of women (Isuigo-Abanihe, 2003).

Many factors prevent women from getting medical advice or treatment when the need arises and the barriers faced by women interfere in seeking care during pregnancy and at the time of delivery. Sociological and institutional factors also favour African men in matters affecting marital and family life. As custodians of the interest of their lineage and the protectors and providers for their families, they make the majority of decisions pertaining to family life. In most communities, women's socio economic status is significantly low to enable such women to contribute meaningfully to family discourse that might lead to improvement in her maternal health. The implication of such an action in a male dominated society is that the activities that influence maternal outcomes are taken for granted ultimately resulting in maternal crises.

Male dominance often subjects women to repeat child bearing at short intervals either to satisfy their husband's quest for a large family size or as a means of adjusting to the very high infant morbidity and mortality in the state. The situation is aggravated by cultural beliefs and practices and a poor medical delivery system that hinders access and the use of hospital facilities during emergencies. The practice of polygamy among families in Northern Nigeria is another strong factor that influences maternal mortality. According to Abdurraheem et al (2016), in most polygamous families, women compete with other co-wives in terms of the number of children to bear.

Successive governments have made efforts at reducing the rate of maternal mortality and morbidity through improvements in health facilities and maternal care in the hospital. In spite of these efforts there is still a high incidence of maternal mortality among the Hausa speaking people. The beliefs in many of the traditional systems and cultural practices could be said to account for the low patronage of modern antenatal and postnatal clinics that sometimes affect people's attitude towards the use of modern medication. Hence, majority of the people are still found patronizing traditional birth attendants (TBAs).

Based on the above and the increased prevalent rates of maternal mortality in Kano state, the difficulty that some women still pass through in having their new-born babies and the need for social research to be incorporated into practice with the same vigour with which we adopt the results of medical research prompted the researcher to study some of the cultural practices (early marriage, patriarchy, taboos and restrictions, home delivery preference, nutritional status and seclusion) associated with maternal mortality in the rural areas of Kano state, Nigeria.

\subsection{The Aim and Objectives of the Research}

The aim of this study is to examine some of the cultural practices affecting maternal mortality among married women of reproductive age in rural areas of Kano state as well as the effects of such practices on maternal mortality. Specifically the objectives include:

- To examine the relationship between early marriage and maternal mortality in the rural areas of Kano State.

- To examine the role played by reproductive decision making in maternal mortality.

- To examine the role played by home delivery preference on maternal mortality there.

- To suggest ways of improving maternal health in rural areas of Nigeria.

\subsection{The Area of Study}

The study covers some rural areas in some selected local governments in Kano, namely: Kibiya, Shanono, Gaya and Bichi. Bichi is one of the study areas. Its headquarters is located in the town of Bichi. It has an area of $612 \mathrm{~km}$ square and a population of 277,099 , according 2006 population census. The people in the local government area are predominantly Muslims and their major occupation is farming. Shanonois another study area data were gathered from. The local government headquarters is in the town of Shanono. It has an area of $697 \mathrm{~km}$ square and a population of 140,607 in the 2006 census. The major occupation is farming and majority of the inhabitants are Muslims. Gaya local government area is another place where data was collected. This is another local government in Kano. It has its headquarters in the town of Gaya. It has an area of $613 \mathrm{~km}$ square and a population of 201,016 at the 2006 population census. Created in 1976, it shares 
boundary with Wudil local government on the west, Albasu and Takai local government areas in the south, Gabasawa and Ajingi in the North and Jigawa state in the East. The major ethnic group is Hausa / Fulani and the religion of its people is Islam Kibiya local government area, on the other hand, is situated in the north-east of Kano state about 62kms away from the state capital. The local government has its headquarters in Kibiya town and is dominated by the Hausa/ Fulani. Kibiya local is bounded to the eastern part by Garko local government area, to the west by Rano local government area, to the north by Bunkure local government area and to the south by Tudun Wada local government area in Kano state. Kibiya local government area has a population of about 207,419 by 2006 National population figures. The major occupation of the people is farming and the people are predominantly Muslims.

\section{Methodology of the Study}

The study used a mixed method otherwise known as the triangulated approach. Survey research method was used and this involved using standardized tools of data collection specifically the questionnaire. To augment the findings of the survey, qualitative methods were employed and these are the In-depth Interview (IDI) and the Focus Group Discussions. The choice of the triangulated method was due to the nature of the research, which is descriptive. The collected qualitative data complemented and clarified the quantitative findings by helping to identify common theses.The cross-sectional survey design was used as the research design for this study. It collects data to make inferences about a population of interest at one point in time. These respondents consist of four target groups.

The first target group are women of reproductive age, who are between the ages of 15 and 49. One thousand one hundred and twenty (1120) women were administered with questionnaires out of which one thousand one hundred and eight (1108) responded. A multi-stage selection sampling process involving cluster and simple random methods was used in selecting the respondents. The first stage of the sampling process was the selection of local government areas for the research. Four were selected using purposive sampling, two from each of the political senatorial zones considered as the zones consisting of morerural local government areas. These are Shanono, Bichi, Gaya and Kibiya.

The second stage was the selection of the study locations, which consist of four (4) locations from each of the four selected local government areas. Census enumeration areas in each were considered as clusters and four (4) enumeration areas, one from each selected locations, were randomly sampled in the third (3) stage of the selection. The fourth (4) stage of the selection was the selection of compounds from the selected clusters using purposive sampling. Households were later selected in the fifth (5) stage and sampled using house-hold listing obtained from National Population Commission. At the sixth and final stage, these selected household were selected for the interview.

\subsection{The Sampling Process for Qualitative Data}

The second target group consists of medical personnel and traditional birth attendants (TBAs), who were respondents for the first in-depth interview (IDI). In selecting respondents for the IDI, one hospital from each of the local government areas was randomly selected. Purposive sampling techniques were used for the selection of participants. In all, thirty six (36) respondents took part in the first IDI.

The third target group consists of the female relatives, friends and neighbours of the women who died as a result of pregnancy and childbirth complication. This group consist of people with privileged information and constitutes participants of the focus group discussions (FGD). Purposive sampling techniques were used to select respondents that participated in the discussions. A total of forty (40) participants for the FGD was drawn from the four local government areas selected. In each of the group, there were ten (10) participants.

The fourth target group are males whose wives had died in the process of pregnancy and child birth. Purposive sampling techniques were used in selecting eight (8) respondents for the second In-depth Interview. These respondents consist of two (2) male respondents from each local government area selected for the study. The reason for the inclusion of this group of people for the study is because they have privileged information by virtue of their closeness to the women who suffered maternal death.

\subsection{Data Collection and Instruments}

A questionnaire, In-depth Interview and Focus Group Discussions were used in collecting the data. The use of coded quantitative responses may not give a detailed result of the motives and reasons for people's actions and feelings. It is for this reasons that both quantitative and qualitative methods of collecting data were used. The use of both quantitative and qualitative techniques is to augment each to obtain comprehensive and more detailed information from the respondents.

The questionnaire had sixty-two (62) close and open ended questions designed in English but administered in Hausa, which is the local language understood by all the respondents. The instrument was translated during the research training and research assistants did on the sport translation while administering to respondents based on the earlier translations. The questionnaires was administered by eight (8) trained female research assistants under a supervisor. The data collection lasted for two weeks.

Similarly, two interview guides were developed. One was administered in English to the health personnel and the same interview guides were to traditional birth attendants in Hausa because most of them could neither speak nor understand English. The second interview guides were administered in Hausa to the husbands whose wives had died in the process of pregnancy and childbirth. Each interview session lasted for about two hours.

The Focus Group Discussion guide was also written in English but administered in Hausa. The discussions were facilitated by a moderator and a note-taker. The average time for each of the FGD session was one hour. The discussions were recorded on a device with the consent of the participants. 


\subsection{Data Presentation Analysis and Discussions of Findings}

The result of the findings obtained from the questionnaire are presented in a tabular form as frequencies, percentages and cross tabulations while qualitative data is reported under appropriate tables as supportive and sometimes as narratives. The presentation is done in sections, based on the objectives of the study and divided into six sections. All the variables related to a particular objective are presented and analyzed under the objective. After the presentation of the facts under various sections in forms of simple frequencies and percentages, the results of the cross tabulations were reported as further analysis.

The total number of the questionnaire distributed to the respondents was one thousand, one hundred and twenty (1120) but one thousand one hundred and eight (1108) were returned. The analysis is based them. The qualitative data generated from the IDIs and FGDs were presented to supplement the quantitative data as appropriate. At the end of the presentations and analysis, a discussion was made on the major findings and attempts were made to relate the findings of this study to other related literature and theories.

\section{Data Presentation}

3.1. Section One: The Socio-Demographic Characteristics of Respondents

This section is on the socio demographic characteristics of the respondents. Their age, ethnic origin, religion and educational level were the characteristics explained. The aim of the section is to provide the demographic picture of respondents under study.

\begin{tabular}{|c|c|c|}
\hline Age & Frequency & Percentage \\
\hline $15-19$ & 173 & 15.6 \\
\hline $20-24$ & 151 & 13.6 \\
\hline $25-29$ & 158 & 14.3 \\
\hline $30-34$ & 153 & 13.8 \\
\hline $35-39$ & 272 & 24.5 \\
\hline $40-44$ & 102 & 9.2 \\
\hline $45-49$ & 99 & 8.9 \\
\hline Total & 1108 & 100.0 \\
\hline
\end{tabular}

Table 1: Age Distribution of Respondents

All the respondents are within the age range of fifteen (15) to forty nine (49) years, as shown in Table 1 . The selection was deliberately done to capture women of reproductive ages. The highest percentage (24.5\%) lies between ages thirty-five to thirty-nine. In addition, those between fifteen to nineteen years constitute fifteen point six percent (56.6\%).

\subsection{The Respondents Ethnic Group}

All the respondents belong to the Hausa/ Fulani ethnic group. This is as a result of the fact that the study was conducted in rural areas of Kano state where majority of the residents belong to that group.

\subsection{Section two: Data on the Reproductive Variables of The Respondents}

\begin{tabular}{|c|c|c|}
\hline Age at Marriage & Frequency & Percentage \\
\hline $13-15$ & 522 & 47.1 \\
\hline $16-18$ & 546 & 49.3 \\
\hline 19 and Above & 40 & 3.6 \\
\hline Total & 1108 & 100.0 \\
\hline
\end{tabular}

Table 2: Respondents Age at Marriage

In Table 2, the respondents' age at first marriage consists of the following: those who got married between the ages of thirteen to fifteen years are forty seven point one percent (47.1\%); those who got married between the ages of sixteen to eighteen, are forty nine point three percent (49.3\%) and those who first got married at age nineteen and above, are only three point six percent (3.6\%). This indicates that majority of the women got married earlier in life between the ages of thirteen to eighteen. This shows that in rural Kano, early marriage is the rule rather than the exception. According to the participants of the focus group discussion (FGD), it is encouraged both by culture and religion. It was also pointed out during the discussions that every parent in the rural area was afraid of his/ her daughters becoming promiscuous, as virginity was still held in high esteem among Muslim communities. To ensure the girls are married off as virgins is, therefore, a priority to parents. Moreover, it is considered a shame to a family whose daughter gets with pregnant out of wedlock this may bring lifelong stigma to the family concerned, as one of the participants mentioned:

In this community every mother protects her daughter jealously to avoid anything akin to moral decadence. We make sure no man has a carnal knowledge of our daughters prior to marriage to avoid a lifetime shame on the family. Once a girl is approaching puberty- anytime from age twelve- we start preparation on how to get her married (FGD: Female: March, 2017). 
A male participant in the IDI conducted is of the opinion that it is his duty as a good father to give his daughter's hand in marriage as soon as she is of age. The participant has this to say.

I married my first wife at the age of fourteen and my second wife at the age of fifteen. One of the two daughters from my first wife was married out at age sixteen. I cannot keep a big daughter like that in my house when I have a wife of her age. To complete my duty, it is an obligation to marry my daughters out as soon as they have suitors, for fear of any adverse consequence that may follow if they are not married early (IDI: Male: March, 2017)

\begin{tabular}{|c|c|c|}
\hline Age at First Birth & Frequency & Percentage \\
\hline $13-15$ & 477 & 43.1 \\
\hline $16-18$ & 560 & 50.5 \\
\hline $19-21$ & 50 & 4.5 \\
\hline 22 and above & 21 & 1.9 \\
\hline Total & 1108 & 100.0 \\
\hline
\end{tabular}

Table 3: Respondent's Age at First Birth

Table 3 above provides a clear picture of the ages of the respondents when they had their first child. Among the, respondents, forty three point one percent (43.1\%) had their first child between the ages of thirteen to fifteen years old; fifty point five percent (50.5\%) between the ages of sixteen to eighteen years, four point five percent (4.5\%) between ages of nineteen to twenty one, and only one point nine percent (1.9\%) at twenty two (22) years and above. This shows that majority had their first child between the ages of thirteen and eighteen. One of the participants of the FGD had this to say: I had my first child when I was fifteen years old. I was in labour for two days and the older women in our household were encouraging me to be brave, saying that it is only by being brave during the birth of my first childthat would I have proven to be a real woman and such an experience would put me through subsequent childbirths. I went through a lot of pain that I never knew I could survive. It was on the third day of going into labour that I was finally taken to the hospital and delivered of a stillbirth baby through caesarian section (FGD: Female, March, 2017).

\section{4: Section Three: Maternal Health Services in Rural Areas.}

\begin{tabular}{|c|c|c|}
\hline Visit to Antenatal Clinics & Frequency & Percentage \\
\hline Visit for all pregnancies & 199 & 18.0 \\
\hline $\begin{array}{c}\text { Visit for only some } \\
\text { Pregnancies }\end{array}$ & 535 & 48.3 \\
\hline Total & 734 & 66.2 \\
\hline
\end{tabular}

Table 4: Respondent's Visit to Antenatal Clinics for all Pregnancies

Table 4 shows that eighteen percent (18\%) of the respondents said they visited antenatal clinics for all their pregnancies while forty eight point three percent (48.3\%) said they only visited antenatal clinics for some of their pregnancies. Some of the reasons given for not attending clinics for all pregnancies have to do with long distance to health centers and lack of financial capability. Some pointed out that they did not need to go for antenatal clinic since they had no health problems. This is as a result of the fact that most of them believed that one only visited health care centres when one was ill.

\begin{tabular}{|c|c|c|}
\hline $\begin{array}{c}\text { Reasons for Not Visiting Antenatal } \\
\text { Clinics for Other Pregnancies }\end{array}$ & Frequency & Percentage \\
\hline No Money & 151 & 13.6 \\
\hline No Health Problem & 171 & 15.4 \\
\hline Husband's Refusal & 82 & 7.4 \\
\hline Mother In law's Refusal & 37 & 3.3 \\
\hline Health Clinic Too Far & 94 & 8.6 \\
\hline Total & 535 & 48.3 \\
\hline
\end{tabular}

Table 5: Respondent's Reasons for Not Visiting Clinic for Other Pregnancies

As shown in The Table 5, thirteen point six percent (13.6\%) of the respondents who did not attend ante-natal clinics for some of their pregnancies mentioned that it was because they had no money to facilitate their going to the clinic, fifteen point four percent (15.4\%) said they had no health problem to necessitate their attendance and eight point six percent ( $8.6 \%$ ) complained of the distance from their homes to the clinic. Seven point four percent $(7.4 \%)$ mentioned that they could not attend antenatal clinics due to their husbands' refusal and three point three percent (3.3\%) said their nonattendance was due to their mother in-laws' refusal to grant them permission to attend such clinics.

During the FGD, some of the participants who did not attend ante natal at all pointed out that their husbands' refusal to permit them to go was largely because it was a family tradition of such husbands. One of such participants said: Pregnancy is a normal process of childbirth and generations of women have gone through such a process successfully without clinical interference. For this reason all women in my compound don't bother to attend antenatal clinics and 
besides our husband would not allow us to do so since we have elderly experienced women in the compound who can take care and advise us on issues pertaining to pregnancy and childbirth (FGD: Female, March, 2017).

An IDI participant stated that:

Many of the pregnant women brought to the clinic are often those with health issue(s) such as malaria, anemia, high blood pressure, leukemia and pre-eclampsia. Some of them are brought in critical conditions. This is because they have the notion that a pregnant woman does not need to go to the clinic except, she is ill (IDI: Female, March 2017).

This point was buttressed by a statement made by a male participant of IDI who said:

Motherhood is a natural process and our grandmothers went through pregnancies and childbirth when there were no hospitals. What then is so special about the process of childbirth which was not in existence then? (IDI: Male, March, 2017)

\begin{tabular}{|c|c|c|}
\hline Usual place of Delivery & Frequency & Percent \\
\hline Home & 837 & 75.5 \\
\hline Hospital & 271 & 24.5 \\
\hline Total & 1108 & 100 \\
\hline
\end{tabular}

Table 6: Respondents' Usual Place of Delivery

Despite the fact that many women in rural areas attend antenatal clinics, most of them deliver their babies at home, as shown in Table 6, which indicated, that seventy five point five percent (75.5\%) of respondents usually delivered their babies at home while only twenty four point five percent (24.5\%) had their babies in health care centres. Those of them who delivered in health facilities said they felt safer with the presence of health personnel and the equipment available in such centres. Those who delivered at home pointed out that delivering in a health facility means having enough money for medication. Some mentioned lack of cooperation from their husbands while others said they were more comfortable delivering within the family with close relatives and people they were used to around them.

\begin{tabular}{|c|c|c|}
\hline Place of Last Delivery & Frequency & Percentage \\
\hline Home & 777 & 70.1 \\
\hline Hospital & 331 & 29.9 \\
\hline Total & 1108 & 100.0 \\
\hline
\end{tabular}

Table 7: Respondent's Place of Last Delivery

From Table 7, a large percentage of the respondents consisting of seventy point one percent (70.1\%) had their last child delivered at home while twenty nine point nine percent (29.9\%) had theirs in hospitals. This shows an improvement in deliveries done in health centres in recent times. Some of the participants in FGD pointed out that the improvement in delivery in health care centres is due to enlightenment and the improved awareness of the benefit of hospital delivery by the respondents. They further pointed out that there could have been more improvement but for the economic downturn of the nation. Some health personnel pointed out that the improvement in hospital deliveries was as a result of frequent campaigns and enlightenment undertaken by government on the benefits of delivering in health centres. One of such personnel had this to say:

The conduct of sensitization tours undertaken by the government to health care centres in the villages help a lot in informing the populace at the grassroots level of the importance of delivering in health care centres. We, the health care givers, are also empowered to conduct house by house enlightenment on the benefits of delivering in a health facility. This has helped in the improvement in number of women that delivered in the health care facility in recent time (IDI: Male, March, 2017).

\begin{tabular}{|c|c|c|}
\hline Preference for Place of Delivery & Frequency & Percentage \\
\hline Home & 863 & 77.9 \\
\hline Hospital & 245 & 22.1 \\
\hline Total & 1108 & 100 \\
\hline
\end{tabular}

Table 8: Respondents' Preference for Place of Delivery

The Place of delivery is a major factor in safe delivery. From Table 8, a large percentage of the respondents' consisting of seventy seven point nine percent $(77.9 \%)$ prefer to deliver at home while only twenty two point one percent (22.1\%) prefer hospital delivery. Those who prefer to deliver at home said they preferred it because in it there is privacy, while others said they felt safer within the family environment. For those who prefer hospital delivery, some said delivery there meant avoiding labour problems, while some of them mentioned that it means having a safe delivery.

The participants in FGD pointed out that delivering their babies at home meant less cost in terms of finance and that they felt safer and more comfortable in their own homes. The health care workers also buttressed this point when they pointed out in the IDI conducted that although a substantial number of women attended antenatal clinics, they still prefer to deliver at home. They said most often, those brought to deliver in the hospital had one health challenge or the other and were usually in critical condition before being brought to the hospital.

A participant of the FGD had this to say; 
I prefer to give birth at home in the midst of my relatives whom I am more familiar with. Incase if death comes, they would help in making sure I die with my faith intact. But in the hospital, relatives and friends are not allowed into labour rooms (FGD: Female, March, 2017).

Another FGD participant had this to say:

Giving birth at home means my husband would not incur any unforeseen expenses. It is cheaper to give birth at home and since other women in my compound deliver at home I cannot be an exception (FGD: Female, March, 017)

In the IDI interview conducted, some of the medical personnel in Kibiya local government area said poverty, ignorance and preference for the squatting position during delivery were reasons why women in the community prefer home delivery.

\begin{tabular}{|c|c|c|}
\hline Causes of Death & Frequency & Percentage \\
\hline Convulsion & 370 & 33.4 \\
\hline Bleeding & 233 & 21.0 \\
\hline Prolonged Labour & 203 & 18.3 \\
\hline Ectopic Pregnancy & 30 & 2.7 \\
\hline Anemia & 105 & 9.5 \\
\hline Ignorance & 25 & 2.3 \\
\hline Lack of Good/Adequate Diet & 8 & 0.7 \\
\hline Total & 974 & 87.9 \\
\hline
\end{tabular}

Table 9: Respondents' view on the Causes of Maternal Death

According to the data in Table 9, convulsion in the view of the respondents is the cause of death in thirty three point four percent (33.4\%) of cases of maternal death, twenty one percent (21\%) died as a result of bleeding; eighteen point three percent $(18.3 \%)$ prolonged labour, two point seven percent $(2.7 \%)$ oectopic pregnancy; nine point five percent (9.5\%) anemia and point seven percent $(0.7 \%)$ lack of adequate diet. The result of the findings shows that convulsion, bleeding and prolonged labour constitute the highest causes of maternal death in the study areas. This is followed by anemia, ectopic pregnancy, ignorance and lack of good dietary intake in order of frequency, as pointed out by the respondents. A medical personnel had this to say as regards causes of maternal death;

Major problems associated with maternal mortality are medical cases such as severe malaria during pregnancy, anemia, high blood pressure, leukemia, hemorrhage, prolonged labour and eclampsia. But most of these cases have pre disposing factors, which had to do with a woman's wellbeing before, during and immediately after childbirth (IDI: Female, March, 2017).

\subsection{Section 5: Reproductive Decision Making}

\begin{tabular}{|c|c|c|}
\hline Freedom to Decide When to Have Sex & Frequency & Percentage \\
\hline Yes & 340 & 30.7 \\
\hline No & 768 & 69.3 \\
\hline Total & 1108 & 100 \\
\hline
\end{tabular}

Table 10: Respondents' Freedom in Deciding When to Have Sex

According to Table 10 above, thirty point seven percent (30.7\%) of the respondents said they were free to participate in decision making, as to when to have sex or not while sixty nine point three percent $(69.3 \%)$ said they were not. The reason for lack of freedom to participate in such decision making, as explained by participants of FGD, ranges from shyness, culture and religion. In the words of a FGD participant,

I cannot engage myself in such discussion with my husband because I don't even know where to start from. I just make myself available when he needs me, otherwise I may incur the wrath of God (FGD: Female, March, 2017).

\begin{tabular}{|c|c|c|}
\hline Freedom to Decide When to Stop Birth & Frequency & Percentage \\
\hline Yes & 398 & 35.9 \\
\hline No & 710 & 64.1 \\
\hline Total & 1108 & 100.0 \\
\hline
\end{tabular}

Table 11: Respondents' Freedom on Deciding When to Stop Birth

From Table 11 above, sixty four point one percent (64.1\%) of the respondents said they were not free to decide when to stop child birth while thirty five point nine (35.9\%) said they were. A participant of the FGD pointed out that; It is God that limits a woman 's offspring and I cannot interfere in such matters. No matter what I do to prevent childbirth, if God wills me to have more children, nobody can stop that. Besides children are special gifts from God and there are women who crave to have such blessings but are unable to have even a single child (FGD: Female, March, 2017). 


\begin{tabular}{|c|c|c|}
\hline Freedom to Attend Antenatal Clinic & Frequency & Percentage \\
\hline Yes & 779 & 70.3 \\
\hline No & 329 & 29.7 \\
\hline Total & $\mathbf{1 1 0 8}$ & $\mathbf{1 0 0 . 0}$ \\
\hline
\end{tabular}

Table 12: Respondents' Freedom in Deciding Whether to Attend Antenatal Clinic or not

From Table 12 above, seventy-point three percent (70.3\%) of the respondents are free to participate in deciding whether to go for antenatal clinic or not while twenty-nine-point seven percent (29.7\%) are not free to participate in such decision making. This shows that majority of the women in these communities are given a free hand when it comes to attending antenatal clinics. As pointed out by some participants in a FGD, we are not restrained from going for ante natal most of the times but even when we are allowed to go, the issue of finances sometimes stop us from attending such clinics. Besides our spouses find it easier to give us permission when going for antenatal but discourage us from delivering in the hospital due to financial expenses involved(FGD: Female, March, 2017).

\begin{tabular}{|c|c|c|}
\hline $\begin{array}{c}\text { Final Decision Maker on Where } \\
\text { to Deliver }\end{array}$ & Frequency & Percentage \\
\hline Husband & 507 & 45.8 \\
\hline Wife & 180 & 16.2 \\
\hline Wife and Husband & 220 & 19.9 \\
\hline Mother Inlaw & 41 & 3.7 \\
\hline Head of The Family & 160 & 14.4 \\
\hline Total & 1108 & 100 \\
\hline
\end{tabular}

Table 13: Making the Final Decision on Where to Deliver

From Table 13 above, forty five point eight percent (45.8\%) of the respondents say the decision of where to deliver their babies is taken by their husband; sixteen point two percent (16.2\%) said the decision is taken by the wives; nineteen point nine percent (19.9\%) said it is taken jointly by husbands and wives; three point seven percent (3.7\%) indicated that it is taken by mothers in-law while fourteen point four percent (14.4\%)pointed out that such decision rest in the hands of the head of the family, who is often the eldest male. This could be attributed to the patriarchal nature of the people in these communities where women are rarely consulted in the process of decision making.

\begin{tabular}{|c|c|c|}
\hline $\begin{array}{c}\text { Decision Maker on Where to Go in Case of } \\
\text { Emergency }\end{array}$ & Frequency & Percentage \\
\hline Husband & 501 & 45.2 \\
\hline Wife & 180 & 16.2 \\
\hline Wife and Husband & 221 & 19.9 \\
\hline Mother in-law & 41 & 3.7 \\
\hline Head Of Family & 150 & 13.5 \\
\hline Others & 15 & 1.4 \\
\hline Total & 1108 & 100.0 \\
\hline
\end{tabular}

Table 14: Making Final Decision on Where to go in Case of Emergency

According to Table 14, forty five point two percent (45.2\%) of the respondents said their husbands decide where to go in case of emergency; sixteen point two percent (16.2\%) said they take the decision alone; nineteen point nine percent (19.9\%) indicated they take the decision jointly with their husbands, three point seven percent (3.7\%) said the decision is made by their mothers in-law while thirteen point five percent $(13.5 \%)$ pointed out that such a decision is usually taken by the head of the family. As pointed out by some of the participants of the FGD held in Shanono and Gaya, the head of the family and mother in-law decide where to go in case of emergency when their husbands are not in town, since most of such men may have gone to look for greener pastures (chirani). Some male IDI participants had the opinion that there are elders in the family who are more knowledgeable in terms of knowing danger signals than them and it is these people that decide if the situation warrants seeking health care from hospitals.

A man interviewed who opines that he decides where to go in case of emergency had this to say:

I decide where to seek for further help in case of emergency because I am the husband and therefore in charge. Besides my pockets help me in making such a decision since it is me that would eventually pay the bills and bear all costs involved in the process of treatment. You know once you seek healthcare from these our hospitals, the first things they demand are some medical items which involves money (IDI: Male, March, 2017).

\section{Discussion of the Findings}

This section contains discussions of the major research findings of the study as well as shows it theoretical and practical implications. The discussions is done based on the objectives of the study in forms of headings starting with early 
marriage, reproductive decision making, taboos and restrictions, home delivery preference, maternal nutrition status and religious practices of purdah, which are the cultural practices associated with maternal mortality in rural areas.

\subsection{Early Marriage}

The result of the study revealed that forty seven percent (47\%) of the girls got married between the ages of 13 and 15years and majority of the respondents (96.4\%) got married by the age of eighteen (18). This indicates that girls in the study areas are given out in marriage at an early age, which makes it a rule rather than an exception. In the same vein, the study discovered that forty three percent (43\%) of the girls in the study area had their first child between the ages of 13 and 15 and by age 18 ninety three point six percent (93.6\%) had already had their first child. This finding on early marriage is similar to the findings of UNICEF (2016), which pointed out that in Nigeria forty three percent (43\%) of women were married off before their $18^{\text {th }}$ birthday and seventeen percent $(17 \%)$ were married before they turn 15. Similarly, the findings of NDHS 2013 shows that $23 \%$ of women aged 15 to 19 are already mothers orpregnant with their first child and young motherhood is the highest in Northwest zone of Nigeria. In northern Nigeria, child marriage is used as a method for preservation of the virtue of girls. The findings of this study reveal that the rationale for the practice of child marriage in the rural areas is to ensure the preservation of virginity of women and also to ensure women do not become pregnant out of wedlock. It was also pointed out by respondents that child marriage protects girls from being promiscuous and protects family honour. This corroborates the findings of Braimah (2014), which states that girls are married off before reaching puberty to avoid the dishonor and shame attached to premarital sex.

\subsection{Reproductive Decision Making}

From the study, it was revealed that the final decision on where to give birth is often made by the husband and the wife is only free to make the decision in only $19.9 \%$ of the cases. The cases of involvement of women in deciding when to have sex, when to stop birth, where to give birth and where to go in cases of emergency are very low in the study areas despite the fact that all such cases involve her wellbeing. During labour and delivery and sometimes in cases of complications, other secondary players, such as parents or in-laws, may make important decisions for the family. Borrowing from Beddada (1982), rarely will the woman delivering make decisions even regarding her own health. This clearly shows the patriarchal nature of the rural areas of northern Nigeria, where women are least involved in decision making. As viewed by liberal feminist philosophy, women in rural areas of Nigeria are disadvantaged through socialization into submissive gender roles and reproductive decision making roles are largely played by men. The culture of the Hausa society passed down to generations encourages submissiveness of women to their husbands especially in terms of reproductive decisions, such as whether to attend health clinic or not when pregnant, during delivery and after delivery.

\subsection{Home Delivery Preferences}

It was revealed in the study that majority of the respondents $(70.1 \%)$ gave birth to their last child at home and $77.9 \%$ showed preference for home delivery. This shows that women in these rural areas still prefer home delivery rather than delivering in health facilities. This is in line with the findings from the Nigeria Demographic and Health Survey of 2008, which says that 73\% of deliveries occurred at home (NpopC, 2009). The Health Belief Model can also be used to explain this preference for home delivery. Among traditional people, the belief that death is predetermined and beyond human control plays a factor in taking preventive measures to health problems. This set of people holds the belief that whether they deliver in a health centre with the most sophisticated equipment or not, when it is time for one to die, the person must die. .

\section{Conclusion and Recommendations}

Based on the foregoing analysis, some cultural practices influence maternal mortality 0in the selected rural areas. Maternal health has been a source of worry and concern to demographers and maternal mortality constitutes a significant burden of ill-health in Nigeria. To understand the problem of maternal mortality as a whole, we must understand the influence of cultural practices on maternal health. Almost all the respondents indicated they are aware of incidences of maternal death and were able to mention causes of these deaths, such as convulsion (eclampsia), hemorrhage, anemia and retained placenta, but found it difficult to believe that some cultural practices are the pre-disposing factors that lead to these causes of maternal death. For this reason women need to be more enlightened on harmful traditional practices that are detrimental to their health. Despite the fact that a substantial number o00f pregnant women in these rural areas attend antenatal clinics, yet they prefer to deliver their babies at home is a thing of concern. This is because traditional birth attendants, who attend to these women, are not well trained and have no modern equipment to adequately arrest any emergency that may arise.

\section{Recommendations}

Based on the findings of this study, the following recommendations are offered. Early marriage was identified as one of the cultural factors that influence maternal mortality of women in the rural parts of Kano state. The Child Rights Act of 2003 puts the age of marriage at eighteen (18) but this law has not been enforced especially in northwest Nigeria. Most often, child brides least educated and live in rural areas. It is therefore the recommendation of this study that marriage should be delayed until a girl reaches at least eighteen. Education for her from child should be encouraged as this would go a long way in preventing the girls getting into marriage at early age and would also have become educated, informed and more enlightened before indulging in the processes of bearing children. Moreover, education would afford her the opportunity to understand how some cultural practices can be detrimental to reproductive health. This can be done if girl- 
child education is encouraged, especially in rural areas. The government should also make and enforcelaws prohibiting the practice of early marriage with stiffer penalties, ranging from long jail terms for offenders.

Women are rarely involved in reproductive decision making. This is a reflection of the patriarchal nature of the rural communities studied. There is the need therefore to encourage and involve women in reproductive decision making through legislation or socialization. Community leaders, religious organizations and even youth forums can be involved in enlightening the populace on the need to involve women in reproductive decision making.

Aggressive and socially relevant programmes on the utilization of reproductive health facilities and opportunities should be encouraged by government and non-governmental organizations for men and women, especially in the rural areas of Kano. The programs should be targeted at creating awareness on the importance of urgent, prompt and good decision making in times of emergencies.

Similarly, the training and retraining of TBAs should constantly be done since they attend to the majority of the deliveries in rural areas, especially remote and underserved communities. The government should design a program and seek for avenues to check on the activities of TBAs periodically. The TBAs must be madeaw are of the complications and signs that could appear during deliveries that might be beyond the limit of their expertise and knowledge. Where women give birth with no one present (NOP) should greatly be discouraged. The awareness of the dangers attached to such a practice should be highlighted during all reproductive health enlightenment programs undertaken, especially at the community level by the health workers in the rural areas of Kano State.

There should be awareness created mostly targeted towards encouraging women to get involved in programs aimed at better reproductive health practices. The Mass media, community meetings and professional associations and other communication channels can be used in this awareness creation. Men should also be encouraged to use their decision making roles and responsibilities on the promotion of awareness of health problems of women. With the use of these programmes, men would be encouraged to take responsibility for the effects of their behavior on women's reproductive health.

Men should be encouraged to give their wives expressed permission to visit healthcare clinics whenever the need arises even in the absence of the husband. This would reduce the chances of women getting into the critical stage of their health before visiting the clinic. It is therefore recommended that programmes on reproductive health should not be targeted at women alone but alongside the men. This can be achieved through meetings and organized discussions between community leaders and men in the communities.

\section{References}

i. Abdurraheem, A., Ilim, M. M. \& Amali, S. (2019). Attitude and Perception of Family Planning among Couples in Rural Parts of Nigeria: A Study of Danmusa Local Government Area of Katsina State. International Journal of Innovative Research and Development, 8(3).

ii. Adamu, M. Y., Hamisu, M. S. \& Nalini. S. (2003) Maternal mortality in northern Nigeria: a population-based study. European Journal of Obstetrics, Gynaecology and Reproduction 109(2), 153-159.

iii. Apav-Igba, L., Ilim, M.M. and Abdurraheem, A. (2019). Socio-cultural Factors Affecting Human Fertility in Nigeria. Being a Paper Accepted for Publication in FUDMA Journal of Social Sciences.

iv. Beddada, B. (1982). Traditional practices in relation to pregnancy and childbirth In Baashir, T. Bannerman R. Rushwan H, Sharaf I, eds. Traditional practices affecting the Health of Women and children, Vol. 2, Cairo: WHO Eastern Mediterranean Regional Office Technical Publication; pp47-50

v. Braimah, T. S. (2014). Child marriage in northern Nigeria. African Rights Journal, 8(2) 24.

vi. Isuigo-Abanihe, U.C. (2003b). The Socio-Cultural context of High fertility among Igbo women. International Sociology, 9(2).

vii. National Population Commission, NPopC, (2009). Nigeria Demographic and Health Survey (NDHS), Carverton Maryland, USA.

viii. National Population Commission, NPopC, (2014). Nigeria Demographic and Health Survey (NDHS), Carverton Maryland, USA.

ix. $\quad$ UNFPA (2018).Support to Traditional Birth Attendants. Evaluation Report, 12. UNFPA, New York.

x. UNICEF (2016) State of the World's Children.

xi. USAID (2008). Maternal morbidity. http/ www.unfpa.org/mothers/ morbidity. Accessed December 14, 2014.

xii. WHO World Health Statistics 2014 Geneva, World Health Organisation 2014

xiii. World Health Organisation (WHO), (2011), Guidelines on preventing early pregnancy and poor reproductive outcomes among adolescents in developing countries.

xiv. World Health Organization (1997). Coverage of Maternity Care. A listing of Available Information. World Health Organization, Geneva. WHO/ RHT/ MSM/ 96.28.

xv. World Health Organization (2010). Trends in maternal mortality,1990 to 2008. Estimates developed by WHO, UNICEF, UNFPA and the world bank, Geneva. [http:/ www.who.int/ reproductivehealth]

xvi. World Health Organization (2018). Fact sheet: Maternal Mortality, Department of making pregnancy safer.

xvii. World Health Organization, WHO (2013). Essential Nutrition Actions: Improving maternal, newborn, infant and child health and nutrition.

xviii. Yar'zever S.I. (2014) Temporal Analysis of Maternal Mortality in Kano State, Northern Nigeria: A Six-Year Review. American Journal of Public Health Research 2(2) 62-67.

xix. Yar'zever S.I.,\&Duze M.C, (2013). Factors Influencing the Attitudes of Hausa Male Parents Towards Girl Child Education in Kano, Nigeria, Journal of Research on Humanities and Social Sciences (IISTE) 3(2). 
xx. Yar'Zever, S.I. (2010). Epidemiology Study of Families Knowledge, Attitude and Practices on Infant Teething in Kano, American Journal. Of public health research. 2(3).

xxi. Yar'Zever, S. I. \& Said, I. Y. (2013). Knowledge and Barriers in Utilization of Maternal Health Care Services in Kano State, Northern Nigeria. Journal of Biology and Medical Science Research, European Centre for Research, Training and Development. 1(1) 1 - 11. 